(D) https://orcid.org/0000-0001-9489-8509

Российский государственный гуманитарный университет

Кафедра теоретический и исторической поэтики

125993 Москва

Миусская площадь, 6

enkelinaiivius@gmail.com

\title{
СТРУКТУРА ФОТОПОЭТИЧЕСКОГО: «ФОТОКАМЕРА СТРАШНАЯ ВЕЩЬ...» БОРИСА ХЕРСОНСКОГО
}

\author{
PHOTOPOETICS AS STRUCTURE: 'A CAMERA \\ IS A SCARY THING...' BY BORIS KHERSONSKY
}

The article is dedicated to the analysis of the poem "fotokamera strashnaya veshch..." ['a camera is a scary thing...'] by Boris Khersonsky. The analysis is divided into three levels encompassing the sound, vocabulary and grammar, and the plot. The structural features of the poem are identified and it is shown that they conform to the peculiarities of photopoetics, such as transgressiveness, discreteness, isolation, documentary character and metonymic treatment of the object. The sound-level analysis reveals a lack of order, in view of which rhyme becomes the ordering mechanism of the poem. Syntagms corresponding to the syllabotonic meter are broken by enjambements, some of which also violate stanza boundaries. The density of consonants and vowels and the rhythmic scheme allow the author of the paper to highlight the weak and strong points of the poem, as well as the principles of the relations between stanzas: they can form crosswise or regular pairs, both opposed and conjoined. The poem's vocabulary features two thematic fields, one relating to the camera, the other to the soul. The camera is mostly connected with death and immobility, it can capture only scattered fragments, while the soul, on the contrary, is living, moving, it can see and contains memories. Combining the two groups in metaphors and personifications can be perceived as an attempt to overcome antinomies and at the same time as acknowledging that it is impossible to do so. The initial situation is that of the horror of the camera. Mechanically organised memory (photo album) is lost, and the human soul proves to be more capacious and more perfect, which helps to negate and thus ultimately overcome the initial situation. The lyrical subject cannot appear in the text, and where he strives to do this, he turns out to be helpless, the weakest link in the plot. In the first stanza, the world captured by the camera falls apart and becomes insignificant - it loses its uniqueness due to the infinity of automatic clicks (the camera is alive). The second attempt to collect this world within the framework of the album proves futile (the soul is dead). In the third stanza, the situation is reversed (the soul is alive). The poem ends, in essence, with the death of the camera, because its gaze lacks viability. The turning point in which the subject becomes aware of himself in the process of reflection is the moment of differentiation between his vision and the vision of the camera: it does not see, but the lyrical subject does. Thus, photography, which appears to the reader 
primarily as a topic, becomes the basis of the poetics of the entire text. Throughout the poem, we are faced with how, for example, metric-rhythmic and syntactic discreteness is overcome with the help of stanzaic unity, how fragmentation of imagery turns into integrity through oxymoronic combinations; grammatical isolation and limitations of vocabulary are not absolute; the transgression of the lyrical subject, forcing him into losing his identity, is overcome by gaining his own vision. Finally, object metonymy - replacing memories with photographs - ends with the defeat of the camera and the triumph of the integrity of the subject.

Keywords: the visual in literature, photography in literature, photography in lyric poetry, photopoetics.

Статья посвящена анализу стихотворения Бориса Херсонского «фотокамера страшная вещь...» Анализ разделен на три уровня: звуковой, лексико-грамматический, сюжетный. Выявляются структурные особенности стихотворения, которые подчиняются особенностям фотопоэтики, таким как трансгрессивность, дискретность, замкнутость, документальность и метонимия объекта. Звуковой уровень показывает недостачу упорядоченности, и потому упорядочивающим текст элементом является рифма. Синтагмы, соответствующие силлаботоническому метру, разрываются анжамбеманами, которые нарушают также строфические границы. Характер звуковой организации (аллитерации и ассонансы) показывает усиление консонантизма и, напротив, ослабление вокализма. Плотность согласных и гласных звуков и ритмическая схема позволяют выделить слабые и сильные места стихотворения, а также принципы соотношения строф: перекрёстное или парное, как сопоставленное, так и противопоставленное. На лексико-грамматическом уровне выделяются два тематических поля. Первое связано с фотоаппаратом, второе - с душой. Фотоаппарат связан со смертью, неподвижностью, он может запечатлеть лишь фрагменты, тогда как душа, напротив, живая, подвижная, она видит и содержит воспоминания. Метафоры и олицетворения, построенные на соединении лексики двух полей, могут восприниматься как попытка преодолеть антиномии и одновременно как невозможность сделать это. Исходная ситуация ужаса перед фотоаппаратом, при встрече с которым механически организованная память (фотоальбом) теряется, а человеческая (душа) оказывается шире и совершеннее, в конце преодолевается через отрицание. Лирический субъект не может появиться в тексте, а там, где он пытается это сделать, оказывается самым беспомощным звеном сюжета. Парное сопоставление - это фотоаппарат/душа, перекрестное - мертвое/живое. В первой строфе мир, запечатленный фотокамерой, распадается на части и становится незначительным - он утрачивает уникальность из-за бесконечности автоматических щелчков (фотоаппарат живой). Во второй попытка собрать этот мир в рамках альбома оказывается тщетной (душа мертвая). В третьей строфе ситуация переворачивается (душа живая). Завершается стихотворение, по сути, смертью фотокамеры (последнее слово как точка - «склеп»!), потому что ее взгляд нежизнеспособен: «он глух и слеп». Событие, в котором субъект осознает себя в процессе рефлексии, - это момент разграничения своего видения и видения фотоаппарата: он не видит - а лирический субъект видит. Так, фотография, появляющаяся для читателя в первую очередь как тема, становится основой поэтики всего текста. На протяжении всего текста мы сталкиваемся с тем, как, например, преодолевается метрико-ритмическая и синтаксическая дискретность с помощью единства строфики, как в образах та же раздробленность через оксюморонные сочетания превращается в целостность; лексико-грамматическая замкнутость и ограниченность лексических средств не абсолютна; трансгрессия лирического субъекта, заставляющая его лишиться своего «я», преодолевается обретением собственного зрения; наконец, объектная метонимия - замена воспоминаний фотографиями - оканчивается поражением фотоаппарата и торжеством субъектной целостности.

Ключевые слова: визуальное в литературе, фотография в литературе, фотография в лирике, поэтика фотографического. 
Статья посвящена анализу структуры фотопоэтического на примере одного стихотворения Бориса Херсонского. Под фотопоэтикой мы понимаем тип визуального в литературе ${ }^{1}$, комплекс структурных особенностей текста, связанных с упоминанием в нем фотографии и процесса, относящегося к фотографированию, которые могут воплощать тот или иной признак фотографии как таковой, ее трансгрессивность, дискретность, замкнутость, документальность и метонимию объекта ${ }^{2}$.

Наша задача - показать, как фотопоэтика может проявляться на всех уровнях лирического текста, а также как эти уровни взаимодействуют. Приведем текст стихотворения Херсонского, сопроводив его ритмической схемой:

фотокамера страшная вещь каждый уносит кусок

реальности шесть на девять или иной размер

мир стёрся о щёлканье объективов нескончаем поток

к останкам истории мумиям или обломкам вер

всё это дышит ещё откроешь фотоальбом увидишь стену какой-то крепости но какой всё равно не вспомнишь хоть бейся в неё лбом

название костью в горле стоит и на кой

эти странные древние имена душа это склад портретов мелодий номеров стихотворных строк старая добрая сказка на новый недобрый лад люди колонной в собор как раньше в острог

под щёлканье фото вспышки то тут то там но аппарат не слышит не видит он глух и слеп

режет мир на прямоугольники и светлый надмирный храм для него всё равно что тёмный подземный склеп ${ }^{3}$.

$$
\begin{aligned}
& 2-2-2-0-2-2- \\
& 1-2-1-1-2-1- \\
& \text { (или } 1-2-1-4-1-) \\
& -0-2-4-3-2- \\
& \text { (или 1-2-4-3-2-) } \\
& 1-2-2-2-2-1- \\
& \text { (или 1-2-2-5-1-) } \\
& -2-2-1-4- \\
& 1-1-2-1-4- \\
& 2-1-2-2-0- \\
& \text { (или } 2-1-2-3-) \\
& 1-2-1-2-2- \\
& 2-2-4-1-2- \\
& 1-2-3-2-1- \\
& -2-2-2-2-1- \\
& -2-2-1-2- \\
& 1-2-1-2-1- \\
& 3-1-2-2-1- \\
& \text { (или -2-1-2-2-1-) } \\
& -1-4-3-2-1- \\
& 2-2-1-2-1-
\end{aligned}
$$

${ }^{1}$ С. П. Лавлинский, Н. М. Гурович, Визуальное в титературе, [в:] Поэтика: словарь актуальных терминов и понятий, под ред. Н. Д. Тамарченко, Москва: Издательство Кулагиной: Intrada 2008, с. 37-39.

${ }^{2}$ Подробнее о свойствах фотографического в литературе см.: М. Д. Самаркина, Фотограбическое в иикле романов о Гарри Поттере, «Артикульт» 2016, № 24(4), с. 67-72.

${ }^{3}$ Б. Херсонский, Мраморный лист, Москва: АРГО-РИСК: Книжное обозрение 2009, [электронный ресурс] http://www.vavilon.ru/texts/khersonsky2.html\#7 [24.06.2020]. 
Как видно из схемы, стихотворение написано 6-ударным дольником $^{4}$ с мужской клаузулой и переменной (0-2) анакрусой (три слога только во второй строке последней строфы). Несмотря на вариативность постановки ударений, мы, подчиняясь прочтению первой строки как первому впечатлению от текста, охарактеризуем именно эту версию. В строках первого катрена - шесть ударений, второго - пять, в трех строках третьего и четвертого катренов пять ударений и одна, третья строка, шестиударна. О концах речевых отрезков сигнализирует мужская перекрестная рифма. Общее количество ударений в строфах позволяет говорить о том, что первые два катрена противопоставлены, третий и четвертый - сопоставлены.

Ритмическая схема дольника обнаруживает присутствие инерции трехсложников, причем в первой и третьей строфах она выражена сильнее, чем во второй и четвертой.

Характер ритмической неупорядоченности привносят в текст строчные и строфические анжамбеманы (при этом пунктуация отсутствует). В первой строфе: «каждый уносит кусок / реальности», «нескончаем поток / к останкам истории». Между второй и третьей строфами: «и на кой / эти странные древние имена». Между третьей и четвертой: «люди колонной в собор как раньше в острог / под щелканье фото вспышки то тут то там». В четвертой: «и светлый надмирный храм / для него всё равно что тёмный подземный склеп».

Если обратиться к фонике строф, то самые частотные согласные звуки будут распределяться следующим образом: в первой строфе к:м:н:р:с:т 11:10:9:9:10:11 (анаграмма слов «фотокамера» и «к останкам»), во второй строфе к:н:с:т 8:9:8:11 (анаграмма «стену какой-то»), в третьей к:н:р:с:т 8:10:13:9:12 (анаграмма «странные» и «стихотворных строк»), в четвертой л:м:н:п:р:т 8:7:13:7:7:14 (анаграмма «аппарат» и «прямоугольники»). Как видим, аллитерация в целом построена на одних и тех же звуках. На их фоне выделяется группа щелевых глухих звуков ф:ш:щ 12:11:4. Они сконцентрированы в самых первых словах стихотворения, а также - в слове «не вспомнишь» (второй катрен). Аллитерация из этих звуков, на наш взгляд, миметически передает работу фотоаппарата, его щелчки. Этих фонем нет в последних строках первых двух строф и в предпоследних строках третьего и четвертого четверостиший.

${ }^{4}$ Каждая строка здесь распадается на два сегмента-полустишия, причем бо́льшая часть сегментов имеет структуру трехиктного дольника. Такой стих получил название сегментного дольника, а его многочисленные образцы мы находим в поэзии И. Бродского. См.: С. Е. Ляпин, «Сегментный» дольник: к описанию метрических новаций Иосифа Бродского, «Вестник Московского университета. Сер. 9, Филология» 2011, № 6, с. 36-46. 
Отметим, как группируются согласные внутри строф. В первой строфе 21:18:23:20 (82), во второй - 16:17:21:16 (70), в третьей - 18:25:19:19 (81), в четвертой - 19:20:25:23 (87). Динамика их распределения позволяет увидеть как строки, выделяющиеся внутри строф, так и две строфы с наиболее низким и наиболее высоким консонантизмом.

Распределение ударных гласных по строфам следующее: в первой строфе а:э:и:о:у:ы 6:5:4:8:1:0 (24), во второй - а:э:и:о:у:ы 1:3:2:13:0:1 (20), в третьей - а:э:и:о:у:ы 8:2:0:10:1:0 (21), в четвертой - а:э:и:о:у:ы 3:5:3:7:2:2 (21). Совокупное распределение гласных в стихотворении - 61-49-57-53. В плане ассонанса самая сильная строфа - первая, а слабая - вторая. Таким образом, эти строфы контрастны, а третья и четвертая изоморфны.

Рифма - точная. В первом катрене: кусок - поток (достаточная), размер - вер (достаточная); во втором: фотоальбом - лбом (богатая), какой - кой (богатая); в третьем: склад - лад (богатая), строк - острог (богатая); в четвертом: там - храм (достаточная), слеп - склеп (богатая). Четыре из них построены на дополнительном созвучии (их мы выделили жирным). Как видим, принцип соотношения строф соответствует предыдущим нашим наблюдениям. Интересно, что во втором четверостишии рифма звучит как бы эхом, отголоском, а в третьем и четвертом, напротив, рифмующееся слово звучит сильнее первого. Слабая позиция второй строфы, подтверждаемая анализом предыдущих аспектов, компенсируется рифмой.

Строфика - традиционная, с перекрестным типом рифмовки: абаб. Четверостишия синтаксически не замкнуты, а строфические анжамбеманы позволяют задаться вопросом, насколько мотивирована строфическая сегментация текста.

Итак, наиболее упорядочивающим текст элементом является рифма. Синтагмы, соответствующие силлабо-тоническому метру, разрываются анжамбеманами, которые нарушают также строфические границы. Характер звуковой организации (аллитерации и ассонансы) показывает усиление консонантизма и, напротив, ослабление вокализма. Плотность согласных и гласных звуков и ритмическая схема позволяют выделить слабые и сильные места стихотворения, а также принципы соотношения строф.

Следующий уровень анализа - лексико-грамматический.

Выделяются два тематических поля. Первое связано с фотоаппаратом. К нему относятся следующие слова: вещ, кусок, размер, к останкам, мумиям, обломкам, о щелканье, объективов, поток, это склад, ботоальбом, стену, колонной, в острог, аппарат, вспьики, на прямоугольники, склеп, стерся, не сльиит, не видит, режет, уносит, страшная, нескончаем, глух, слеп, темньий, подземный, каждый, иной, шесть на девять, все равно. Второе тематическое поле связано с душой: реальности, мир, истории, крепости, вер, название, имена, 
портретов, мелодий, номеров, строк, люди, в собор, храм, дыиит, откроешь, увидишь, странные, древние, стихотворных, светлый, надмирный.

Сфокусируемся на повторах: в первой и четвертой строфах повторяется слово «щёлканье», образующее композиционное кольцо; омонимичный повтор «всё» - «всё равно» (вторая строфа) - «всё равно что» (четвертая) дает кумуляцию значений от начала к концу; корневые повторы «фотокамера» (первая строфа) - «фотоальбом» (вторая) - «фото» (четвертая) и пропуск в третьей строфе, где появляется душа, чье наполнение противопоставлено наполнению фотоальбома; повторы «мир» (первая строфа) - «мир» - «надмирный» (четвертая, причем в одной строке), с одной стороны, повторяют кольцо «щёлканья», а с другой - выстраивают любопытное отношение внутри стихового ряда, который, как мы видели, выбивается из четвертой строфы: фотоаппарат режет на прямоугольники и мир, и светлый надмирный храм.

Первое, на что мы обращаем внимание, - оппозиция живого и мертвого, заданная существительными «люди» - «останки», а также их свойствами, обозначенными глаголами «увидишь» - «не видит». Второе - выстраивание этой оппозиции по вертикали «верх - низ», также представленной существительными и относящимися к ним прилагательными («надмирный храм» - «подземный склеп»). Прилагательные выстраивают, помимо этого, ценностную оппозицию («светлый» - «темный»). Существительные, относящиеся к фотокамере, обозначают материальную реальность (вещь), а те, что относятся к душе, - нематериальную (название); к фото также относятся слова, несущие семантику дискретности: кусок, обломки, прямоугольники, режет, шесть на девять.

Кроме того, есть слова и выражения, занимающие срединное положение. Они выражают либо неопределенность, либо отношения подобия, уравнивая противоположности: «хоть бейся в неё лбом», «костью в горле стоит», «какой-то», «не вспомнишь», «как раньше», «то тут то там». Следует отметить идиоматичность некоторых из них: «биться лбом о стены», «костью в горле» во втором катрене и «старая сказка на новый лад» в третьем. Эти иносказания приобретают буквальный смысл: стена принадлежит крепости, название нельзя вспомнить и произнести, оно «застряло» в горле, добрая сказка о мире рассказывается на недобрый лад с помощью фотографий. Вместе с тем это также обозначение лексических рамок, свидетельствующих о скованности и ограниченности уже не зрения, а языка перед фотографией.

Интересно рассмотреть образы, выраженные словосочетаниями и предложениями, которые составлены из двух семантических полей: «кусок реальности», «останкам истории», «обломки вер», «душа это склад», «люди колонной в собор». В них происходит контаминация живого и мертвого, смешение и неразличение раздробленного и целого, статики 
и динамики: реальность, история, вера членятся под взглядом фотоаппарата, наполнение души подобно помещению склада, а люди в очереди превращаются в колонну собора. Вместе с тем такая трансформация - это путь к обретению целостности: стихотворение заканчивается не обломками и обрывками, а образами храма и склепа.

Один из способов создания подобных образов - олицетворение. Именно фотоаппарат активно воздействует на реальность («режет мир»), а мир и человек по отношению к нему пассивны («мир стёрся о щёлканье»). Несмотря на это, камеру нельзя назвать живой - в отличие от людей, она не видит и не слышит.

Примечательно ведут себя местоимения - личные и определительные, относящиеся к фотографии, неопределенные и указательные, относящиеся к предметам окружающего мира. Причем в ряде моментов местоименные разряды смешиваются. Личные местоимения, определяющие говорящего субъекта, в тексте отсутствуют.

Как было отмечено при анализе фоники, в слабой позиции находится второе четверостишие. Если соотнести это с распределением частей речи, то можно увидеть, что вторая строфа - единственная, в которой появляются глаголы второго лица единственного числа («откроешь», «увидишь», «не вспомнишь»). Оппозиция «зрение человека - слепота фотокамеры» формируется в том числе тем, что «аппарат не видит» (четвертая строфа). При этом третья строфа - единственная, лишенная глаголов, хотя тематически относится к «душе».

Таким образом, тематическая композиция текста может рассматриваться как антиномия динамики и статики, живого и мертвого, целого и дискретного, нематериального и материального, мира души и мира вещей. Их соединение может восприниматься как попытка преодолеть антиномии и одновременно как невозможность сделать это. Кроме того, динамика на уровне лексики соотносится с изменениями в области фоники, и анализ одной системы объясняет другую: ритмические характеристики акцентируют семантические и синтаксические единицы, принципиальные для понимания текста.

Теперь перейдем к анализу лирического сюжета.

Следует пояснить, что под лирическим сюжетом мы понимаем систему событийно-ситуативных элементов лирического произведения, данную с позиции лирического субъекта в процессе развертывания его рефлексии; для его анализа мы используем категории лирического субъекта, события, ситуации, мотива, пространства и времени ${ }^{5}$.

${ }^{5}$ В. Я. Малкина, Событие и сюжет в тирическом стихотворении («Небывалая осень построила купол высокий...» А. Ахматовой), «Новый филологический вестник» 2012, № 3(22), с. 19. 
Лексический анализ показал отсутствие местоимения «я» в тексте и наличие глаголов, обозначающих обращение к некоторому «ты», за которым может стоять лирический субъект. Можно говорить об имплицитном лирическом «я», которое смотрит на себя отстраненно, не видит себя и лишь указывает на вещи вокруг.

Время стихотворения представлено глагольными формами настоящего несовершенного, прошедшего совершенного и будущего в виде настоящего совершенного. Будущее формирует ситуацию разглядывания («откроешь», «увидишь», «не вспомнишь»). Настоящее («уносит», «дышит», «не слышит», «не видит», «режет») - формы существования фотоаппарата и фотографии в мире. Прошедшее («стёрся») - констатация состояния реальности. Кроме этого, есть синтагмы, подразумевающие наличие глагола, но опускающие его либо за ненадобностью, либо в целях экономии языковых средств («фотокамера страшная вещь», «душа это склад», «люди колонной в собор»), поэтому мы будем такие случаи также относить к настоящему. Отсутствие глаголов делает фотографирование в настоящем происходящим всегда. Оно никогда не заканчивается и не имеет ценности для будущего, для того, кто будет смотреть на снимки.

Пространство стихотворения, как мы уже заметили, выстраивается по вертикали, причем вертикаль эта имеет ценностную и эмоциональную окрашенность со стороны лирического субъекта - то, что для фотоаппарата безразлично, для субъекта имеет четкие границы. Но появляется эта горизонталь только в двух финальных строках.

Первое четверостишие утверждает главную тему рефлексии лирического субъекта: «фотокамера страшная вещь». Вспомним, что эти слова выделены ритмически и сопровождаются аллитерацией, ключевой для всего текста. Лексика первого четверостишия («кусок», «останки», «обломки») определяет главное свойство фотокамеры - превращать живое в мертвое через дискретность. Страх перед фотоаппаратом, согласно первой строфе, - это страх потерять целостность восприятия мира. Все последующие четверостишия посвящены преодолению этого страха. Четвертая строка так же, как и первая, сохраняет метрическую основу трехсложника - в данном случае амфибрахия. С точки зрения стихотворной формы, первая стро$\phi а$ - законченная и целостная, что противоречит ее содержанию.

Второе четверостишие соотносит объективный и объективирующий взгляд фотоаппарата с субъективной жизнью через мотив памяти. Эта строфа, как отмечалось, самая «слабая» с фонетической точки зрения, но при этом единственная, в которой присутствует субъект. Несмотря на звукопись, повторяющую начало текста, содержание второй строфы противоположно первой. Страх лирического субъекта объясняется здесь еще и тем, 
что он ничего не может противопоставить деструктивной силе фотоаппарата; снимки, которые он разглядывает в альбоме, «дышат», но ни о чем ему не говорят. Обезличенная фотоаппаратом память разрушает целостность личности субъекта.

Третья строфа (предельно статичная) через анжамбеман продолжает содержание предыдущей, в ней также говорится о памяти. При этом мы наблюдаем семантическую трансформацию: «душа это склад». Содержание такого склада - «имена», «портреты», «мелодии», «стихи» - в отличие от фотоальбома, может быть и нематериально, не привязано к дискретным образам, сконструированным фотоаппаратом, и потому оно наполнено бо́льшим личным смыслом для субъекта, и чем дальше, тем более они абстрактны и не визуальны.

Наконец, четвертая строфа, как и третья, через анжамбеман и с помощью тематических повторов возвращает нас к первой строфе и теме фотографии, на сей раз - к событию преодоления страха перед фотографией. Последнее слово стихотворения «склеп» рифмуется со «слеп», что позволяет субъектному началу текста утвердить себя в мире: слепой фотоаппарат не видит и потому он мертв, в отличие от меня. Последние две строки могут иметь двойное прочтение: с точки зрения синтаксических отношений и с точки зрения единства и тесноты стихового ряда. Первое - фотоаппарат безразличен ко всему сущему, и потому он его умерщвляет. Второе - фотоаппарат не видит, и потому мир - его склеп, место захоронения, могила.

Начало стихотворения утверждает предметный мир, который тем не менее способен преобразовывать окружающую реальность; субъект появляется во втором четверостишии, и он, помимо того, что не эксплицирован, довольно пассивен. В третьем и четвертом катренах происходит перестановка: субъектная пассивность и созерцательность становятся преимуществом перед зрением объекта.

Мотив памяти, который оказывается статичным миром вездесущих фотографий, связан исключительно с личностью говорящего субъекта, а не с историческими событиями. Однако фотография оказывается лишь симулякром памяти, потому что она замещает память о предметах, местах и людях памятью о помещенных в альбом фотографиях:

Фотография перестает отсылать к своему референту, замыкая наши зрительные воспоминания на фотографических образах. В результате спонтанная, живая (имеющая своим источником опыт прямого (телесного) взаимодействия с вспоминаемым) зрительная память замещается воспоминаниями о фотографических образах

${ }^{6}$ С. А. Лишаев, Помнить фотографией (к анализу фотографической конструкиии памяти), «Вестник Самарской гуманитарной академии. Серия Философия. Филология» 2009, № 1(5), c. 35. 
Сюжетную динамику стихотворения можно описать, следуя логике как парного, так и перекрестного сопоставления четверостиший, к которому мы прибегали ранее. Исходная ситуация ужаса перед фотоаппаратом, при встрече с которым механически организованная память (фотоальбом) теряется, а человеческая (душа) оказывается шире и совершеннее, в конце преодолевается через отрицание. Лирический субъект не может появиться в тексте, а там, где он пытается это сделать, оказывается самым беспомощным звеном сюжета. Парное сопоставление - это фотоаппарат/душа, перекрестное - мертвое/живое. В первой строфе мир, запечатленный фотокамерой, распадается на части и становится незначительным - он утрачивает уникальность из-за бесконечности автоматических щелчков (фотоаппарат живой). Во второй попытка собрать этот мир в рамках альбома оказывается тщетной (душа мертвая). В третьей строфе ситуация переворачивается (душа живая). Завершается стихотворение по сути смертью фотокамеры (последнее слово как точка - «склеп»!), потому что ее взгляд нежизнеспособен: «он глух и слеп». Событие, в котором субъект осознает себя в процессе рефлексии, - это момент разграничения своего видения и видения фотоаппарата: он не видит - а лирический субъект видит.

Сделаем выводы.

Очевидно, что рассмотренные структурные уровни взаимосвязаны и их динамика позволяет проследить смысловое развитие текста.

Фотография, которая появляется для читателя, в первую очередь, как тема, составляет основу поэтики текста. В процессе чтения стихотворения мы наблюдаем, как единство строфики преодолевает ритмическую и синтаксическую дискретность, как благодаря оксюморонным сочетаниям раздробленность образов превращается в целостность. Лексико-грамматическая замкнутость и ограниченность лексических средств не абсолютна, трансгрессия лирического субъекта, заставляющая его лишиться своего «я», преодолевается обретением собственного зрения. Наконец, объектная метонимия - замена воспоминаний фотографиями - оканчивается поражением фотоаппарата и торжеством субъектной целостности.

Разумеется, мы не утверждаем, что наш анализ исчерпывает проблему фотопоэтики в лирическом тексте, но позволяет, как нам кажется, глубже понять ее специфику. 


\section{References}

Khersonskii, Boris G. Mramornyi list: italianskie stikhi. Moskva: ARGO-RISK: Knizhnoe obozrenie, 2009. http://www.vavilon.ru/texts/khersonsky2.html

Lavlinskii, Sergei P., Gurovich, Nadezhda M. Vizualnoe v literature. In: Poetika: slovar aktualnykh terminov i ponyatii, ed. N. D. Tamarchenko. Moskva: Izdatelstvo Kulaginoi: Intrada, 2008: $37-39$.

Lishaev, Sergei A. "Pomnit fotografiei (k analizu fotograficheskoi konstruktsii pamiati)”. Vestnik Samarskoi gumanitarnoi akademii. Seriia 'Filosofiya. Filologiya'. No. 1(5) (2009): 12-36.

Lyapin, Sergei E. "'Segmentnyi' dolnik: k opisaniyu metricheskikh novatsii Iosifa Brodskogo". Vestnik Moskovskogo universiteta. Ser. 9, Filologiya. No. 6 (2011): 36-46.

Malkina, Viktoriya Ya. "Sobytie i siuzhet v liricheskom stikhotvorenii ('Nebyvalaya osen postroila kupol vysokii...' A. Akhmatovoi)”. Novyi filologicheskii vestnik. No. 3(22) (2012): 18-22.

Samarkina, Mariya D. "Fotograficheskoe v tsikle romanov o Garri Pottere", Articult. No. 24(4) (2016): 67-72.

\footnotetext{
\begin{tabular}{|l|l} 
& @ by the author, licensee Lodz University - Lodz University Press, Lodz,
\end{tabular} 